Supporting Information

\title{
Thermoresponsive Polyurethane Sponges with Temperature-Controlled Superwettability for Oil/Water Separation
}

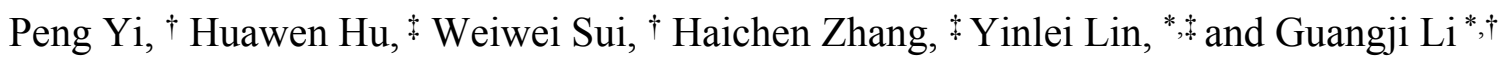
†School of Materials Science and Engineering, South China University of Technology, Guangzhou 510640, P. R. China.

ॠSchool of Materials Science and Energy Engineering, Foshan University, Foshan, Guangdong 528000, P. R. China.

*Corresponding authors: Yinlei Lin, Guangii Li

E-mail addresses: djyllin@126.com(Y. Lin), gjli@scut.edu.cn(G. Li) 

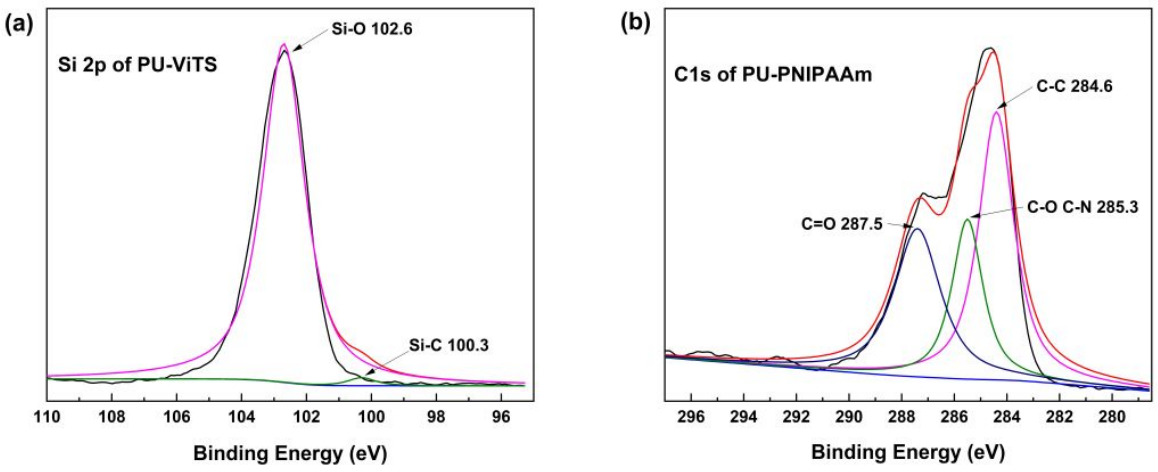

Figure S1 The high-resolution XPS spectra in the (a) Si 2p regions of PU-ViTS and (b) C 1s regions of PU-PNIPAAm.

Table S1 Element composition analysis of PU, PU-ViTS and PU-PNIPAAm surfaces based on their XPS spectra.

\begin{tabular}{ccccc}
\hline \multirow{2}{*}{ Sample } & \multicolumn{4}{c}{ Element content $(\mathrm{wt} \%)$} \\
\cline { 2 - 5 } & $\mathrm{C} 1 \mathrm{~s}$ & $\mathrm{~N} 1 \mathrm{~s}$ & $\mathrm{O} 1 \mathrm{~s}$ & $\mathrm{~S}$ 2 $\mathrm{p}$ \\
\hline PU & 77.70 & 4.35 & 17.95 & 0.00 \\
PU-ViTS & 56.92 & 0.43 & 25.45 & 17.19 \\
PU-PNIPAAm & 70.9 & 11.96 & 16.46 & 0.68 \\
\hline
\end{tabular}

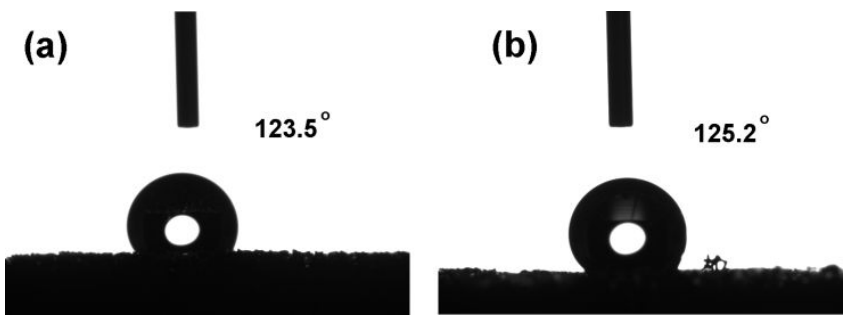

Figure S2 WCA of PU at (a) $25^{\circ} \mathrm{C}$; (b) $45^{\circ} \mathrm{C}$ in air.

(a)

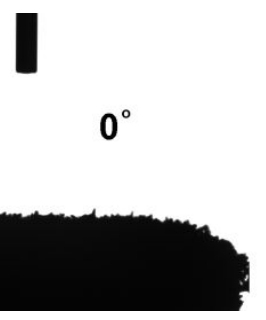

(b)

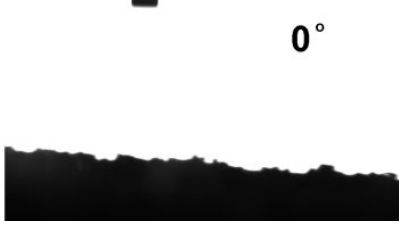

Figure S3 OCA of PU at (a) $25^{\circ} \mathrm{C}$; (b) $45^{\circ} \mathrm{C}$ under water. 


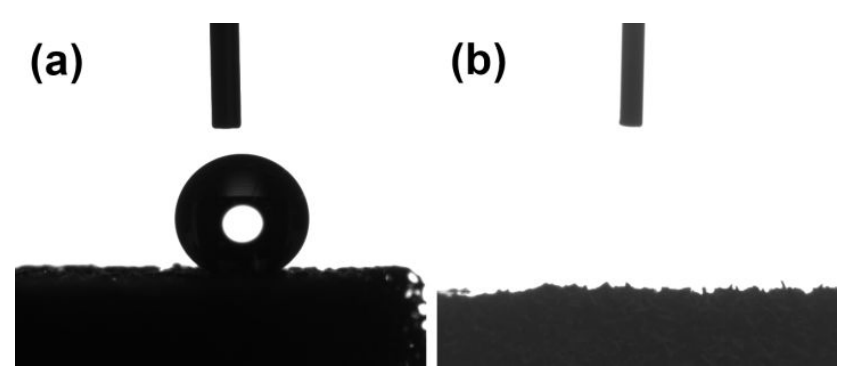

Figure S4 (a) WCA of PU-ViTS; (b) OCA of PU-ViTS.
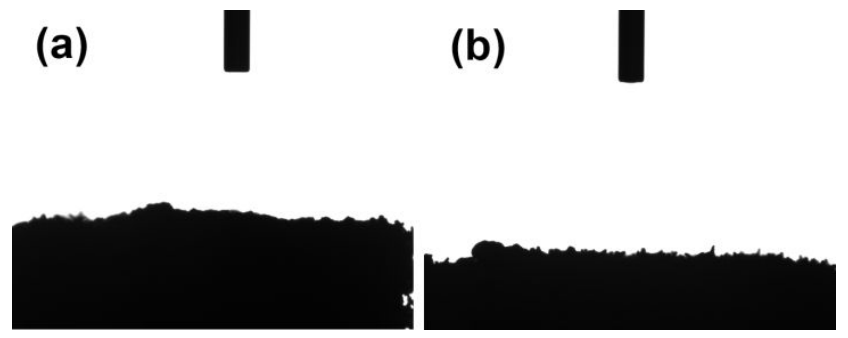

Figure S5 OCA of PU-PNIPAAm at (a) $25^{\circ} \mathrm{C}$; (b) $45^{\circ} \mathrm{C}$ in air.

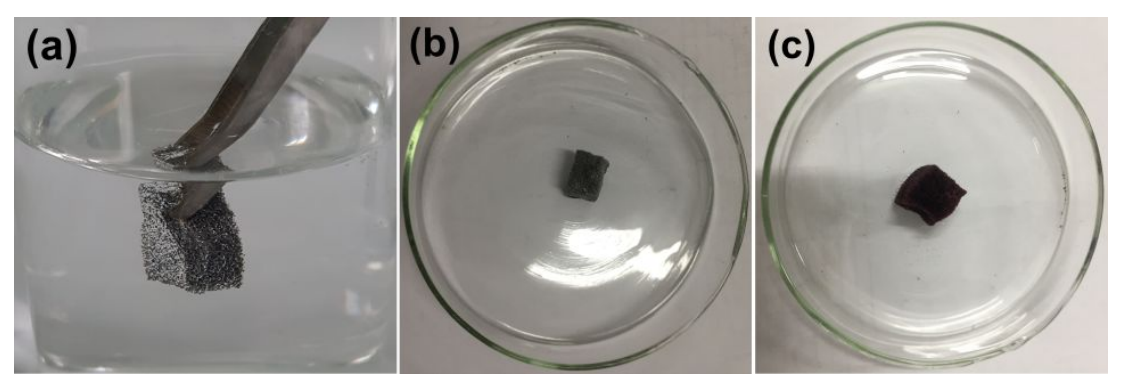

Figure S6 (a) Silver mirror phenomenon of PU-PNIPAAm. (b, c) Different volumes of PU-PNIPAAm (b) before and (c) after being subject to absorption.

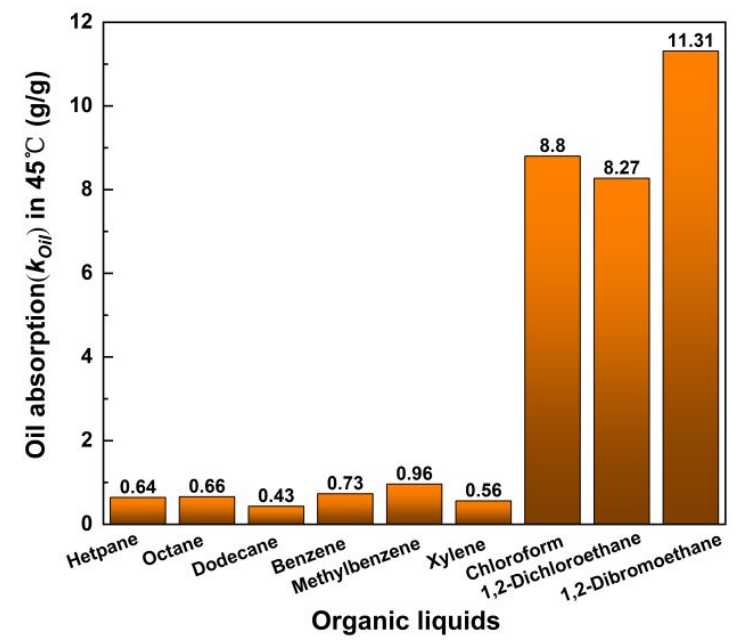

Figure S7 The absorption capacities of PU-PNIPAAm for different oils or organic liquids at $45^{\circ} \mathrm{C}$. 

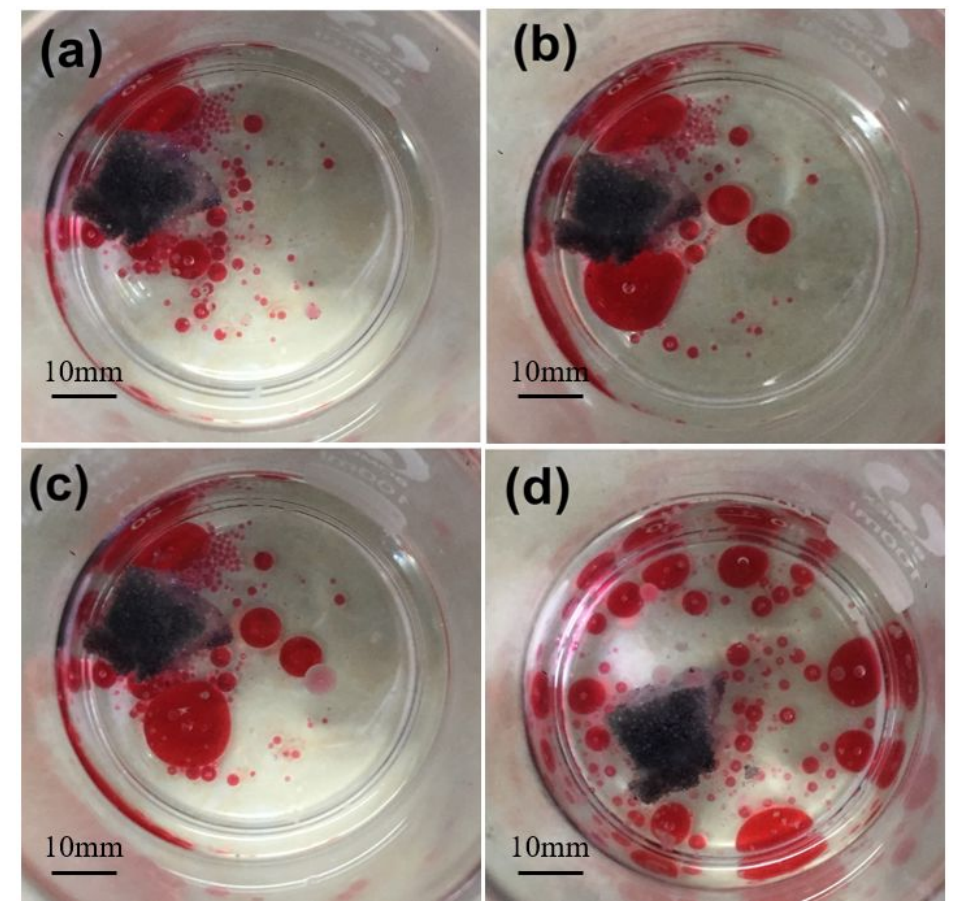

Figure S8 Oil desorption process of PU-PNIPAAm at $25^{\circ} \mathrm{C}$ for $5 \mathrm{~min}(\mathrm{a}) ; 10 \mathrm{~min}(\mathrm{~b}) ; 15 \mathrm{~min}$ (c), and $20 \min (d)$.

Table S2 The recovery efficiency of PU-PNIPAAm in the circulation process of oil/water separation

\begin{tabular}{lcc}
\hline & \multicolumn{2}{c}{ Recovery efficiency (\%) } \\
\cline { 2 - 3 } Cycles & 1,2-dichloroethane & 1,2-dibromoethane \\
\hline 1 & 73.0 & 73.0 \\
2 & 76.6 & 76.3 \\
3 & 79.3 & 79.3 \\
4 & 71.0 & 73.5 \\
5 & 72.1 & 79.5 \\
\hline
\end{tabular}

